\title{
LA RELEVANCIA ECONÓMICA Y POLÍTICA DEL ENFOQUE DE LOS BIENES COMUNES ${ }^{1}$
}

\section{Ángel Calle Collado \\ Universidad de Córdoba (UCO) - Comunaria.net}

RESUMEN: Este trabajo aborda la relación histórica entre las diferentes olas de movilización desde la década de los años cincuenta y la creciente problematización de los cercamientos de los comunes. Observamos que, progresivamente, los comunes constituyen una referencia de acción para propuestas económicas y políticas que trascienden el enfoque clásico de manejos comunales o comunitarios. Hoy en día, la biodiversidad, el agua, el conocimiento o el acceso a tecnologías comunicativas, son ejemplos de prácticas caracterizadas por la creación de instituciones que cooperan para mantener un bien (físico, social) y reproducirlo de forma accesible. Cambia y a veces se difumina el concepto de comunidad. Pero no ocurre así con los métodos de autogestión y cogestión que siguen inspirándose en El gobierno de los comunes, según subrayara Ostrom.

Palabras ClaVe: movilización, comunes, bienes, cooperación.

RESUM: El treball aborda la relació històrica entre les diverses ones de mobilització des dels anys cinquanta i la problematització creixent dels encerclaments dels comuns. Hi observem que, progressivament, els comuns constitueixen una referència d'acció per a propostes econòmiques i polítiques que ultrapassen l'enfocament clàssic de maneigs comunals o comunitaris. Ara com ara, la biodiversitat, l'aigua, el coneixement o l'accés a tecnologies comunicatives, són exemples de pràctiques caracteritzades per la creació d'institucions que cooperen per a mantenir un bé (físic, social) i reproduir-lo de manera accessible. Canvia i de vegades es difumina el concepte de comunitat. Però no passa el mateix amb els mètodes d'autogestió i de cogestió, els quals encara s'inspiren en El govern dels comuns, segons va remarcar Ostrom.

Paraules Clau: mobilització, comuns, béns, cooperació.

1. Agradezco especialmente los comentarios de Manuel Delgado, de la Universidad de Sevilla, y José Luis Fernández Casadevante, Cooperativa Garúa, compañeros de viaje en Comunaria. 
ABSTRACT: This paper addresses the historical relationship between the different waves of mobilization from the 50s onwards and the increasing problematization of enclosure of the commons. We observe how commons increasingly constitute a reference for economic and political proposals that go beyond the classical approach of communal or community management. Today, biodiversity, water, knowledge or access to communication technologies are examples of practices characterized by the creation of institutions that cooperate to maintain a "common" (physical, social) and keep it accessible. While the concept of community changes and is sometimes blurred, this is not the case with the methods of self-management and co-management that continue to draw from Governing the Commons, as Ostrom highlighted.

KeYWORDS: mobilization, commons, cooperation.

\section{Bienes comunes y ciclos de movilización}

L

os bienes comunes son hoy una herramienta que es vista con curiosidad por quienes, frente a la crisis civilizatoria, pensamos que puede ayudar a plantear otras referencias de economía, otras instituciones sociales, otros lazos algo más humanos. ${ }^{2}$ Elinor Ostrom obtenía el premio Nobel de Economía, en 2009, por sus contribuciones, entre otros aspectos, al análisis económico institucional, reflejadas en su famoso texto sobre El gobierno de los comunes. Con el análisis de experiencias de todo el mundo, nos invitaba a recordar, más bien lo hacía a los apóstoles del neoliberalismo, que existen experiencias de manejo sustentables más allá del Estado y del mercado capitalistas. De hecho, estas experiencias son y han sido la base de sustentabilidad social y ambiental de muchos territorios. La economía se hace a través de instituciones sociales, como hoy el neoliberalismo se hace desde la Unión Europea, la Organización Mundial del Comercio y el Fondo Monetario Internacional, además de entornos educativos, publicitarios y de investigación para las élites. Y en concreto, respondiendo al trabajo de Hardin de 1968 «La tragedia de los comunes», Ostrom demostraba que el mundo está plagado de experiencias exitosas (en clave de reproducción de recursos y bienestar)

2. Ver números especiales en Ecología Política $\mathrm{n}^{\circ}$ 45, Documentación Social $\mathrm{n}^{\mathrm{o}} 165$. 
donde manejos comunitarios han podido solucionar conflictos, asegurar el acceso a un bien compartido (pesca, montes, agua, tierra) y redistribuirlo según criterios variables de solidaridad.

El capitalismo se reproduce a base de cercamientos, sirviéndose para ello de un marco institucional internacionalizado. Hoy en día, la Organización Mundial del Comercio promueve patentes de semillas en lugar de potenciar la riqueza de la biodiversidad cultivada que ha venido posibilitando la alimentación del mundo. El Fondo Monetario Internacional alienta privatizaciones en recursos como el agua, los montes o en el acceso a la salud o a la educación. Grandes centros comerciales se asientan como lugar de relación o de construcción de referencias y jerarquías sociales a través del consumismo. Facebook o Youtube o Google se alzan como herramientas comerciales que median nuestras interacciones. Todo ello de forma autoritaria, sin contar con la legitimación social, sin establecer pactos o compensaciones, imponiendo doctrinas neoliberales a través de medios de comunicación o en las escuelas. De esta manera, los sucesivos cercamientos del capitalismo, y de prácticas autoritarias e insustentables que resuenan en él, están lejos de proponer libertad y conseguir bienestar para el mundo.

Todo ello ha incentivado retomar perspectivas de anclaje sociocomunitario y perspectiva cooperativista: se buscan nuevas miradas y nuevas instituciones que valoricen el protagonismo social, los saberes más localizados y lógicas más inclusivas y menos depredadoras. Bajo el paraguas de bienes comunes, simplemente comunes (bienes compartidos, commons), procomunes (modelos de gestión sociocomunitaria) o instituciones del bien común, aparecen reflexiones y prácticas que se ven reflejadas en esa cooperación orientada a la reproducción de la naturaleza y de bienes sociales, indispensables para dicha cooperación. No hay semilla local si no hay saber asociado que lo cultive, no hay democratización de la política si no la hay del conocimiento y de las tecnologías que le sirven de reproducción, no hay sustentabilidad ambiental si no hay prácticas que relocalicen nuestras formas de consumo, etc. Las economías para los bienes comunes serían una expresión desde lo económico, de las búsquedas de una intensificación de la democracia y de un afán de sustentabilidad en nuestras prácticas y valores para potenciar lo común (bienestar) y los comunes (medios). Iniciativas que se entrelazan con otras desde campos muy diversos como: cultura, urbanismo, bienes digitales, salud, derechos colectivos, nuevas tecnologías de la comunicación, 
mercados, comunidades rurales y urbanas, etc. ${ }^{3}$ La producción de software libre, la creación de conocimiento compartido en Internet, las luchas sociales por el control social y comunitario del agua o de los montes, el auge en la construcción de formas de producción y de consumo cooperativos y de acento local, el desarrollo de espacios sociales destinados a la autogestión, las propuestas de cogestión en materia de salud o de educación por parte de las comunidades beneficiarias de estos servicios, entre otros, son ejemplos de esas innovaciones económicas y políticas, marcadas por el cooperativismo y la relocalización de los satisfactores de nuestras necesidades humanas. Se rescata el trabajo de Ostrom, pero esta vez poniendo el acento en los manejos cooperativos para democratizar y reproducir bienes, sean sociales o ambientales, más que en desarrollar comunidades cerradas (hoy muy abiertas y atravesadas por múltiples identidades para la gestión de determinados recursos) que satisfagan todas nuestras necesidades.

El enfoque de este texto se apoya, principalmente, en la antropología económica: ¿Qué está haciendo colectivamente la gente para construir otros mundos desde la perspectiva amplia de los bienes comunes (ambientales y cooperativos)? Mirada que se complementa con la ecología y la economía política: las élites organizan el mundo, nuestro mundo biológico y simbólico, para su beneficio y de forma irresponsable para todas las personas. Y donde no podía faltar una visión de los comunes fuertemente entrelazada al devenir de las culturas políticas que están protestando en las calles de forma paralela a la construcción de otras relaciones económicas. Los ciclos de movilización social nos ayudan a entender la presencia y las propuestas de otras economías. La crítica del capitalismo actual no puede entenderse sin los aportes y las construcciones realizadas por el movimiento obrero, el feminista o el ecologista. En este sentido, y para realizar una introducción sucinta, el enfoque de este trabajo (y de las experiencias que se analizan en él) se correspondería con una tercera ola de construcción de bienes comunes en el marco de los distintos referentes históricos, asociados en gran medida a las olas de protesta frente a las crisis provocadas por el capitalismo:

1. Enfoque inicial de los comunes como recursos de una comunidad, generalmente naturales, pero que constituyen la base de circulaciones económicas y políticas de mayor escala. Primeros cercamientos del capita-

3. Ver Mapping the commons (Hess, 2008): http://ssrn.com/abstract=1356835. 
lismo, a los que luego se añadiría una crítica sobre cercamientos sobre cuidados, cuerpos, espacios de socialización. Periodos de acumulación que tendrían su expresión más notable en los procesos descritos por Karl Polanyi (El sustento del hombre) cuando campesinos o productores artesanos son excluidos del acceso a recursos ambientales fundamentales para sus economías (tierras de labranza, pastos, agua, bancos pesqueros cercanos a las costas, etc.).

2. Bienes comunes concebidos más allá de un territorio concreto en el que se desarrollan las relaciones económicas de una comunidad. Hablamos del planeta y de subsiguientes periodos capitalistas donde se amplían los cierres a espacios masivos y de interconexión del sistema-mundo. Se potencian a partir de los años 80 con el despegue de la ola neoliberal y la llamada globalización: de la revolución verde vamos pasando a los sistemas agroalimentarios con base en imperios económico-financieros de fuerte impulso en las biotecnologías; puntos de gran biodiversidad en el planeta son materia de codicia de empresas, en particular farmacéuticas; la disputa por recursos globales, particularmente energéticos pero también el agua comienza a ser motor de la geoestrategia de las grandes potencias que dan lugar a guerras en el centro de África, Oriente Medio o a grandes desplazamientos violentos en la India o en América Latina; el propio espacio exterior queda apropiado para fines no discutidos socialmente y de interés de las grandes empresas de telecomunicación. Como actores destacados, contaríamos con el movimiento obrero más clásico y sus propuestas cooperativistas, pero también el mundo rural e indígena que plantea nuevas cuestiones y nuevas formas de autogobierno en el territorio.

3. Y, finalmente, una etapa que se superpone a las anteriores, las cuales no desaparecen, y que, en el marco de una globalización financiera asentada y fuertemente contestada desde inicios del siglo XXI, nos hablan de la emergencia de los nuevos movimientos globales y su crítica sobre el control de bienes cooperativos (espacios, lazos y tecnologías para la socialización y la reproducción social); y que cuentan con una mayor presencia del ecologismo político en sus planteamientos. Ocupar las calles, producir cooperación en Internet, politizar extensamente el consumo o la 
invisibilización de los cuidados que sostienen otras economías, proponer soberanías alimentarias o estrategias de decrecimiento para garantizar la reproducción democrática de bienes ambientales, alimentar un cooperativismo más allá de las estructuras formales del Estado y la economía capitalista, entre otras iniciativas, son ejemplos de la percepción de que los cierres se han proyectado ampliamente sobre lo social y sobre las bases de nuestra vida.

Existe, pues, una asociación entre politización creciente de los bienes comunes y el surgimiento de nuevos ciclos de movilización y de entender la propia política (Calle, 2013). Hecho que permea también los análisis y la literatura que aborda el problema de los bienes comunes. De la primera visión proveniente de una economía institucional o de una antropología económica (Ostrom, el propio Polanyi anteriormente), encontramos a principios del siglo XXI referencias sobre una segunda fase de cercamientos (Boyle, 2003) o de apropiación de recursos a escala planetaria (Ricoveri, 2012; Petrella, 2009). De esta evolución se asientan hoy tres grandes líneas de aproximación a los bienes comunes, las cuales considero muy relevantes para comprender e impulsar nuevas prácticas desde abajo en lo económico y en lo social:

- Las miradas comunitarias desde la economía institucional, las cuales incluyen visiones derivadas del marxismo, más en la economía política. Ostrom se establece como referente, pero también situaría aquí a toda la antropología económica que ha estudiado las formas tradicionales de economía solidaria ancladas en relaciones de «alta sociabilidad» (ver Núñez, 2009), clásicos que introdujeron sus reflexiones sobre economías asentadas en el don o el regalo (Malinowski), el potlach (Mauss) o la reciprocidad y el intercambio solidario (Polanyi).

- Bienes comunes percibidos desde la economía política o práctica para describir, fundamentalmente, la ampliación de cercamientos del capitalismo. Como autores referentes tendríamos la obra de Marx, Polanyi y, en la actualidad, el geógrafo David Harvey o aquellos que se sitúan detrás de la idea de procomún como rectora de nuevas instituciones (Lafuente, Bollier), con énfasis en la autonomía política derivada de ellas (Hardt, Negri). Se anclan aquí perspectivas de extender esta práctica de cercamientos a lo que hoy observamos en el terreno de los bienes digitales, 
habida cuenta de que Internet es hoy una esfera de comunicación y de conflicto político (ver Sádaba y otros, 2013, etc.).

- Economías para la vida. Lo común no es sólo un recurso: es la existencia y la búsqueda de bienestar, individual y colectivo. Constituyen su sustrato las perspectivas de las economías de los cuidados (ecofeminismos o feminismos de la ruptura) o las ideas que se aproximan al postdesarrollo (decrecimiento, buen vivir, desarrollo endógeno sustentable o a escala humana, etc.).

Estas miradas están correlacionadas con los saltos cualitativos, provocados por la movilización social, en la visión y prácticas de economías sociales. El enfoque de economías para la vida no puede entenderse sin el aporte histórico del feminismo. Pero tampoco sin un presente marcado por la crítica a la mundialización capitalista («el mundo no es una mercancía») y el despegue de los nuevos movimientos globales (Calle, 2005; 2009; 2013). Estas redes críticas, de presencia e intercambios planetarios, entran a politizar globalmente las esferas de participación (crítica de la «política del o» o excluyente) y a plantear demandas globales, se refieran al planeta, a la radicalización de la democracia en nuestras sociedades, a la satisfacción de necesidades «desde abajo». Su mirada y su hacer local se asienta en una cultura que he denominado la «política del y» («los rebeldes se buscan» que dicen en Chiapas). La «política del y» se apoya en la agregación de sujetos desde la diversidad para desarrollar procesos orientados, en principio, hacia una radicalización de la democracia. No es, no absolutamente, una nueva cultura política. Pero sí que se distancia de la «política del o», basada en proyectos identitarios fuertes, más propia del movimiento obrero pero también presente en las corrientes de protesta surgidas en los años 60 y los 70 que enfatizaron la autonomía o la diversidad de luchas sociales.

Los nuevos movimientos globales plantean una reflexión más integral y ampliada de lo que entendemos por territorio y cooperación social. Territorio que se amplía desde el ambiente natural (la base ecológica) hacia los ambientes transformados (el hardware construido) merced al entrelazamiento con nuestros ambientes sociales (el software de ideas, valores y costumbres). Tres territorios en cada territorio, siendo la condicionalidad última la del propio ecosistema, por mucho que nos neguemos a recuperar la conciencia de especie. Y cooperación que tiene en el bienestar y el protagonismo social sus referentes. No se trata de 
una cooperación como la que acontece en la mesa de directivos de Repsol o del Banco Santander, por tanto. Y entiende que se deben reproducir y ampliar las esferas que permiten, de la misma manera, cooperar al resto.

Podríamos ampliar estas nuevas visiones de los bienes comunes con la línea, más mediática que con profundidad teórica o práctica, que inaugura el libro de C. Felber La economía del bien común. A grandes rasgos, podemos afirmar que se asienta en la lógica liberal de los mercados autorregulados, la falacia que criticara en su momento Karl Polanyi. Las instituciones trascienden los mercados y son trascendidas por los conflictos que se dan en la sociedad, por motivos de clase económica, género, religión, edad, cultura, país de procedencia, etc. Algo no reflejado por Felber, quien también presta escasa atención al significado institucional de los trabajos de Ostrom como galvanizadora de una mirada económica centrada en la autorregulación, pero social, no de mercado. En el lado positivo, Felber se desmarca de economicismos como la teoría del egoísmo y apuesta por la solidaridad y la cooperación dentro del mercado para construir un capitalismo, pretendidamente autorregulado, cuyos incentivos sean la sustentabilidad. Y apunta formas de control social de la propiedad y del establecimiento de oligopolios de mercado. Pero sigue apostando por el beneficio como motor social (a través del precio y de un consumo «ético») y propone un plan cerrado de actuación desde arriba y desde lo que hay, reforzando modos de integración capitalistas.

\section{Las economías para los bienes comunes: sustentabilidad y democracia frente a los nuevos cercamientos}

En la actualidad, desde la hibridación de los anteriores referentes, los bienes comunes se ofrecen como herramienta para analizar, por un lado, cercamientos de las élites sobre bienes ambientales y relacionales; y por el otro lado, se nos invita a proponer formas de manejo y (nuevas) instituciones sociales para reproducir y extender dichos bienes. De ahí su auge y su capacidad de invitarnos a pensar las transiciones inaplazables: revoluciones energéticas y ambientales que fuercen cambios político-culturales, y viceversa. De ahí, también, sus límites, al proponer un paradigma que abarca muchas realidades y que aún tiene que enfrentarse a su articulación con «viejos paradigmas» (derechos asentados en los estados, «política del o»), a la necesidad de dar respuestas a diferentes escalas que vayan 
más allá de la autogestión (e incluso de la cogestión con políticas públicas) y a la urgencia de los tiempos que demandan un planeta «lleno» de cosas, afectado por un «vuelco climático», y adentrándose en una era «postfósil». Pero aun así, los bienes comunes están inspirando entrelazamientos de miradas y prácticas entre formas de economías que apuntan a lo solidario (inclusivas), el cuidado socioambiental (somos interdependientes), a formas de consumo colaborativo (de carácter no consumista y sí capaz de compartir lo existente), a la vez que se vincula con el cooperativismo formal (que se orienta a la democratización crítica de la sociedad) y a los tradicionales manejos comunales (base de la propuesta de activar comportamientos y espacios cooperativos para manejar bienes sin apropiarse de ellos).

Los cercamientos del capitalismo, por tanto, generan conflictos en los que situamos el centro de la vida y qué entendemos por ella. Como señalara el filósofo Habermas, el dinero intenta colonizar la vida; la economía convencional nos impone la sustitución de vínculos por el sistema autorreferencial de valores monetarios, como expresa José Manuel Naredo (2009: 57). Convertimos recursos naturales en calor, mientras la economía sigue proyectando crecimientos infinitos, movimientos incesantes de energía, exploraciones cada vez más profundas y contaminantes de bienes fósiles. Allí naufragamos.

Hoy los naufragios se democratizan, ya que los bienes comunes que son depredados constituyen el asiento de nuestros ecosistemas, como el agua, la tierra fértil o las variedades autóctonas que son la base material de nuestra biodiversidad (Klink, 2013). La sociedad del riesgo se extiende (Beck, 2002). Capital y vida entran abiertamente en contradicción, hablemos de crisis de cuidados (Herrero y otros, 2011), o pensemos en el gran vuelco climático que se avecina (Tanuro, 2011). Nuestros hogares se vuelven inestables, nos llenan de incertidumbre, se corroen los vínculos esenciales para la cooperación (Sennet, 2012).

Pero no todo se «democratiza». La Encuesta de uso del tiempo, realizada en 2009, muestra que en los hogares del Estado español la crisis ha intensificado (a través de los recortes en servicios públicos, del incremento de desigualdades de género) la doble carga de las mujeres (Ezquerra, 2013; Torres y Gálvez, 2010). De nuevo es difundido e impuesto el rol de mujer-madre, mujer-para-el-hogar. Un nuevo cercamiento global de cuerpos, hogares y mujeres viene a retomar el cercamiento primitivo que realizara el capitalismo en sus albores medievales, para reforzar hoy un ciclo de acumulación al servicio de las élites (Federicci, 2010). 
En ámbitos relacionales, Internet comienza infelizmente a parecerse al mundo real en materia de control y libertades (Martínez, 2013). Surgen industrias culturales que inspiran nuevos cercamientos en el campo simbólico, del ocio, de la producción artística (Sádaba y otros, 2013). La tragedia del copyright se amplifica. Facebook se parece más a una pecera comercial, aunque posibilite que puedan correr como la pólvora otros gritos, otras convocatorias. La plaza real se impone, al final, como testimonio social del alcance del descontento, de la magnitud de las protestas, Internet calienta pero no quema por sí misma (Candón, 2013; Calle, 2013).

En una mirada centro-periferia, sea norte-sur, oeste-este o países del norte versus países mediterráneos, observamos cómo la acumulación tecnológica, de recursos ambientales y de «capital humano» puede verse como un nuevo cercamiento global. Las deudas externas o los tratados comerciales internacionales actúan como disparador de estos nuevos procesos de acumulación (Plataforma Auditoría Ciudadana de la Deuda, 2013). En el plano mundial, los territorios se conquistan y controlan a base de poder financiero que hace desplazar biomasa, materia y energía a velocidades e intensidades nunca antes conocidas (Carpintero, 2005). A escala más local, las ciudades se rediseñan para acoger funciones determinadas por los intereses de las élites: aquí el descanso según clase socioeconómica, allá el ocio, en el centro o donde convenga el desarrollo turístico, etc. Habitamos, trabajamos y circulamos por espacios según lógicas de zonificación que se expanden desde Estados Unidos a partir de la Segunda Guerra Mundial (Castillo y otros, 2013: 35).

Esta política de nuevos cercamientos es la que abre paso a problematizar (de nuevo) la cuestión social más allá del Estado y del mercado (Subirats, 2012, 2013), sin que eso suponga que dicha perspectiva «resuelva» problemas (globales y globalizados) que tienen que ver con escalas, complejidades y necesidades de autoridades democráticas más allá de los espacios locales y comunitarios (González, 2013). La «transición inaplazable» (ambiental, sociopolítica, tecnoeconómica) nos sitúa en la necesidad de abordar los conflictos políticos desde la interconexión entre: los límites energético-materiales del planeta con respecto al metabolismo capitalista; las revoluciones tecnológicas (emergentes o condicionadas por el vuelco climático y la menor disponibilidad de ciertos recursos); y 
las revoluciones sociales derivadas de la creciente desafección política hacia las democracias autoritarias (ver Calle, 2013).

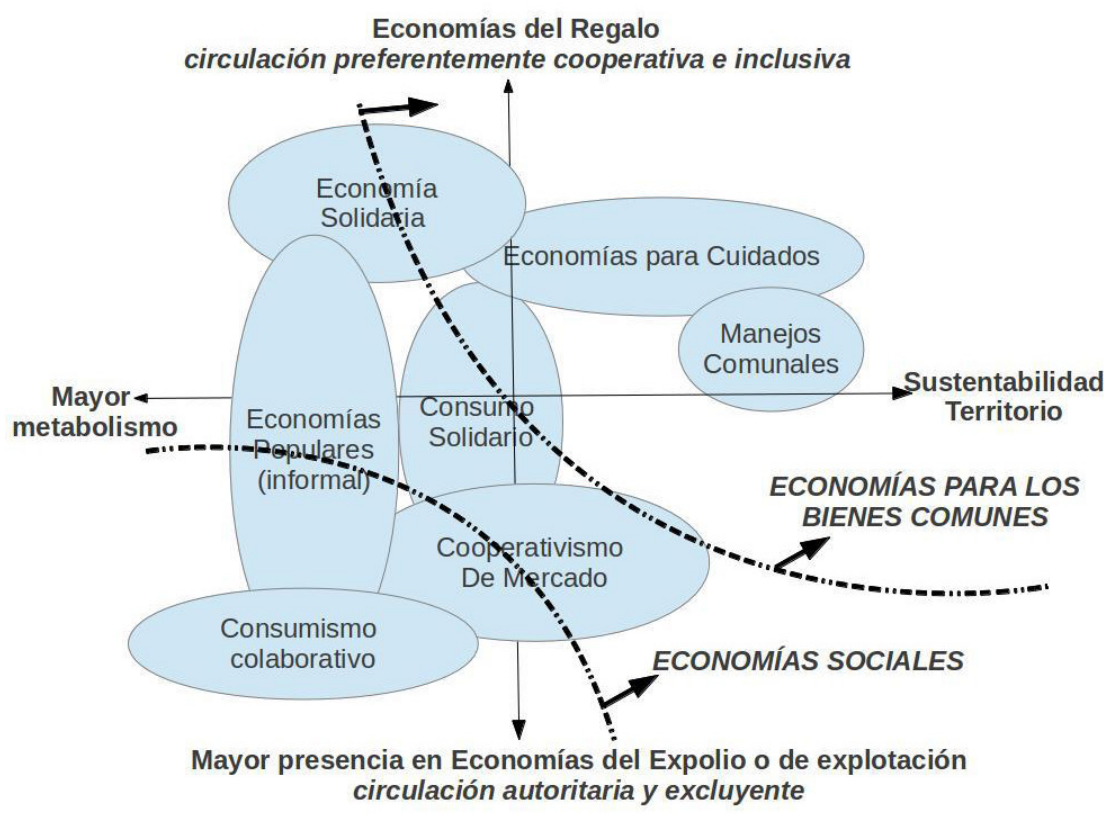

\section{Gráfico 1. Prácticas dentro de la economía social y de las economías para los bienes comunes según dimensiones de reciprocidad y sustentabilidad}

En este contexto de conflicto, de cambios inaplazables y de emergencias de nuevos cooperativismos sociales, es donde las economías para los bienes comunes situarán sus interrogantes, sus formas de hacer, sus procesos. Y lo hacen con el uso implícito y explícito del concepto de bienes comunes. Las economías para los bienes comunes tienen pues muchas expresiones y miradas económicas que parten de una visión transformadora de la economía social (Coraggio, 2009), pero intensifican sus estrategias de cooperación y sostenibilidad sobre la base de un territorio (ambiental y comunitario) concreto. ¿Y de qué economías sociales hablamos como posibles precursoras de estas economías para los bienes comunes? Como tipologías ideales, siempre entrecruzadas y que han de contextualizarse para obtener su sentido real, planteamos como «ramas básicas del árbol de la economía social» las siguientes iniciativas: las cooperativas de mercado, las economías populares, las economías solidarias y de cuidados, el consumo colaborativo (en clave solidaria) y los manejos comunales del territorio. Gran parte de estas iniciativas apuntan a lo que entendemos como «economías para los bienes comunes», como resume el gráfico 1 . 
Dichas economías para los bienes comunes tienen en el cooperativismo (social, laboral) su asiento, con vistas a promover una democratización de nuestras sociedades de forma sustentable. En particular, sitúo en esta perspectiva aquellas iniciativas económicas que buscan poner a disposición de la sociedad bienes ambientales y cooperativos, desde unas lógicas de sustentabilidad ecológica y democratización tanto internas (en la organización del proceso económico) como externas (en la forma en que proponen integrarse o abrirse a la sociedad). Lógicas encuadrables en economías del lugar (Graham-Gibson, 2011), en territorios que constituyen ambientalmente y socialmente su anclaje y su estrategia de reproducción. Estrategia que ha de contemplarse no sólo desde el punto de vista de cerrar circuitos materiales y energéticos, para ganar autonomía y resiliencia en sistemas más amplios (Riechmann, 2013), sino también desde la búsqueda de redes afines dentro de lógicas comunales (más cercanas a manejos tradicionales de los bienes comunes) y de lógicas de nuevo cooperativismo social (más cercanas a los nuevos sujetos políticos).

Las economías para los bienes comunes, por tanto, suponen una actividad socioeconómica que nos habla, explícitamente, de un nuevo y ampliado sentido del trabajo, de la «democracia» y de las aportaciones de «bienes ambientales y cooperativos» al conjunto de la sociedad. En materia de «trabajo» se mueven en clave de facilitar un marco de nuevas relaciones laborales, aunque no siempre se consiga o se persiga situarse al margen de ellas. El empleo formal y la cotización a las arcas del Estado, como agente que redistribuye y garantiza unos mínimos de protección frente a la precariedad, suele considerarse deseable (no siempre) para la existencia de un núcleo dinamizador. Las relaciones cooperativistas hacen que el empleo se inserte en lógicas más horizontales con respecto al establecimiento de condiciones salariales, lo que no evita que surjan empleos más próximos a la precariedad que a la estabilidad. El trabajo también se extiende como motor de la iniciativa a través de las redes de productores y consumidores: artesanos locales, socios de la cooperativa energética, consumidores que se vuelven productores y viceversa, forman parte del cuadro de la economía real que inducen en el territorio estas organizaciones sociales. El trabajo, por último, aparece en ocasiones como voluntariado, incluso como «militancia» según me manifestaba una participante en cubrir horas de servicio en un mercado social. Trabajo entendido como actividad. Pero también trabajo no remunerado y que, si la cooperativa no facilita bienes o cubre necesidades materiales (vivienda o comida, por ejemplo) supone 
la obligatoriedad de redoblar esfuerzos o de conseguir insumos desde otros espacios. Por lo general, se rechaza el apoyo institucional o económico del Estado o del mercado convencional como dinámica de situarse más allá de los mismos. En algunos casos, el voluntariado constituye parte del acuerdo para ser integrante de la actividad: consumidores que aportan horas al trabajo de comercialización o producción de productos; comisiones de integrantes destinadas a evaluar proyectos y su viabilidad financiera; colaboradores necesarios para la puesta en práctica de una actividad cultural; sostenimiento de la difusión o de tareas de formación al interior del proyecto, etc.

La segunda cuestión tiene que ver con las «relaciones democráticas» que se tejen dentro y fuera de la actividad económica. Objetivos y medios en materia de participación o relaciones externas con otros actores sociales y políticos del territorio constituyen puntos del orden del día en asambleas y comisiones. La apertura a admitir nuevos integrantes y las posibilidades de participar de diversa forma son señas de identidad que lo diferencian del cooperativismo clásico y de los sujetos políticos más próximos al aparato institucional estatal. Así mismo, no son ajenas las actividades que tienen la intención de sumarse a críticas sociales en defensa de estos bienes comunes. Ello conduce a campañas y a discursos permeados por ese ideal de democratización extensa de la sociedad, así como la construcción de relaciones más sustentables con la naturaleza. ${ }^{4}$ Por ejemplo, Güifi.net es un operador de telecomunicaciones que se define como un «proyecto colaborativo organizado horizontalmente que aglutina a personas individuales, colectivos, empresas, administraciones y universidades». La Tejedora es un mercado social, en Córdoba, que busca que productores y consumidores dinamicen, no sólo una red de intercambio local, artesanal y ecológica, sino también una democratización de los espacios para relacionarse en la ciudad, para comercializar o realizar actividades culturales. Las monedas sociales o iniciativas como goteo.org también forman parte de esas prácticas atentas a instalar un control comunitario de nuestras formas de intercambio y de financiación. A ellas se unen formas más tradicionales como las cooperativas agroecológicas o la defensa de manejos comunales en montes o bancos pesqueros allí donde pervivieran.

4. Ver webs de experiencias citadas en la tabla 1 del anexo. 
El tercer aspecto, que caracteriza estas economías para los bienes comunes, y que quizás constituye el rasgo más característico dentro de las economías sociales, es su explícita tarea de reproducir y «poner a disposición social bienes ambientales y bienes cooperativos». Se trata de un sentido de acción colectiva que se opone a los movimientos de «cierre» que se dan en el capitalismo; o que trata de enfrentar las estrategias de dominación dentro de estructuras patriarcales o neocolonialistas. Los anteriores ejemplos son ilustrativos de ese actuar para romper cercamientos y reproducir bienes (ambientales, de cooperación, de conocimiento) de manera que, lejos de agotarse, queden más y mejor disponibles bajo criterios de justicia social.

Las economías para los bienes comunes ofrecen nuevos satisfactores que nos conducen a un nuevo metabolismo, por un lado, más armónico y consciente con respecto a nuestros límites ambientales. Y por otro lado, sus principios y modos de integración en la sociedad trascienden la mera circulación de bienes y de servicios más ecológicos. En efecto, también circulan o pasan a circular en la sociedad un nuevo software relacional (valores y actitudes que enfatizan la solidaridad y la cohesión territorial) y un nuevo hardware socioambiental (satisfactores, redes y espacios de cooperación).

Las economías para los bienes comunes son, potencialmente, embriones de una nueva sociedad. No por sí mismas. Ya comenté que los primeros pasos para una transición humana se están sirviendo en una mesa de cuatro patas: la intervención en las instituciones políticas, en distintos planos, pero asentándose en un municipalismo democrático; la construcción de un nuevo sindicalismo que frene y regule las relaciones que el capital impone actualmente; el desarrollo de articulaciones entre las mareas de protesta que beben del protagonismo social en contra de la agenda neoliberal; y, finalmente, estas economías sociales y sustentables que democraticen a la par que hagan más habitable el planeta y los espacios de socialización (Calle, 2013). Pero sí que son importantes por dos razones. La primera: crean y animan a pensar otras economías. La segunda: al asentarse en reciprocidades, territorios concretos y proponer vínculos de proximidad ( $\sin$ excluir el autogobierno de otros vínculos más globales) crean «más sociedad que la economía de la redistribución (más propia del Estado) y del intercambio (típica del mercado)» (Gónzalez, 2013: 51). 
Las cuestiones pendientes, relativas a obstáculos y límites de estas iniciativas, y que habrán de abordar en el futuro estas iniciativas, enfocadas a una promoción de bienes comunes en sentido amplio (ambientales y cooperativos), tienen que ver con:

- La problematización del trabajo y su relación con el capitalismo existente, no sea que estas iniciativas sean «agujeros negros» que nos devuelvan a la galaxia de los (pocos) acomodados y las (mayorías) excluidas, o una visión del trabajo que eluda e invisibilice las economías de los cuidados o las depredaciones ambientales y sociales en otros territorios.

- Los límites de escala, para que dichas experiencias no se conviertan en «islitas», de élites o de proyectos cerrados, presas fáciles de una convivencia subalterna con un capitalismo depredador, como ocurre con muchos procesos cooperativos que trabajan en Internet para las grandes empresas transnacionales de la comunicación.

- La construcción de otras culturas de participación y de relación dialógicas (procesos desde abajo) ancladas en la horizontalidad y la autogestión de nuestras iniciativas sociales, que puedan navegar también en ambientes de cogestión de otras iniciativas sociales más grandes o de políticas públicas.

- La capacidad de producir para ser y para satisfacer nuestras necesidades humanas, que no conviertan estas experiencias en meras «estufitas» (que calientan y producen sociabilidad para minorías) dentro de un capitalismo etiquetado como «del bien común», un capitalismo verde con un buen marketing social, anclado, sin embargo, en la eliminación de instituciones sociales que permitan la gestión democrática de la economía, y que insistan, por el contrario, en la reproducción de valores monetarios y mercantiles, de jerarquías y de insustentabilidades.

- La reconstrucción de lazos sociales, e incluso las redes sociocomunitarias, sin incorporar dinámicas de control por una minoría, de aislamiento, de jerarquización o de exclusión (por condición socioeconómica, género, cultural); el reto no es construir una sociedad de tribus, donde cada individuo es responsable la búsqueda de su comunidad, si no aumentar el empuje social del cooperativismo y de la radicalización de la democracia. 
- Y finalmente, reforzar su capacidad para promover una transición humana que tenga en cuenta los viejos satisfactores asumidos por la sociedad (anclados en derechos sociales, políticas públicas), la necesidad de reformas urgentes (transición energética, solidaridad ante la creciente exclusión) y haga de la diversidad una fuerza creativa «desde abajo» para cambiar globalmente, sin hacer aún más líquidas y fragmentadas las alternativas contemporáneas: los retos de «la política del y», en definitiva.

Conviene subrayar entonces que algunas de las iniciativas que se situarían bajo el rubro extendido (y deformado en muchos casos) de «economía social», aun partiendo de estrategias de cooperación y de protagonismo social, se insertan en polos competitivos y depredadores bajo lógicas capitalistas. Tal es el caso de cooperativas mercantiles (como mera «fórmula jurídica-empresarial»). $\mathrm{O}$ el consumismo colaborativo (acceso a bienes de consumo por parte de una élite que se articula en red) que se distinguiría de un consumo solidario que busca cambiar relaciones o permitir accesos a un bien por parte de todo el mundo. No siempre, por tanto, bajo el concepto de cooperativismo e incluso de bien común se nos propone una democratización extensa de las relaciones económicas, de la satisfacción de nuestras necesidades básicas. Sino, más bien, se construyen nuevos «nichos de mercado» o de «organización empresarial» adaptados a las demandas de mayor autonomía o a las posibilidades que ofrecen las nuevas tecnologías.

Por ahora, gran parte de las iniciativas y miradas tejidas alrededor de los bienes comunes construyen en dirección opuesta a las lógicas depredadoras del capitalismo global y el Estado autoritario, seguidor y fiel legitimador de las agendas neoliberales. Desde este paradigma, más allá del Estado y del mercado, pero más acá de las necesidades humanas y las bases de la sustentabilidad fuerte y la cooperación social, se siembran innovaciones para evitar una transición dolorosa (excluyente, con nuevos cercamientos para una élite) y avanzar en una transición humana (inclusiva, radicalmente democrática). En concreto, nos sirve para adentrarnos en alternativas a través de la visibilización de cercamientos de manera más amplia por parte de las élites, la necesidad de trascender las lógicas neoliberales de privatización, la utilidad de explorar encuentros entre cogestiones (derechos de ciudadanía, propiciados por instituciones públicas) y autogestiones (cultivos sociales para satisfacer necesidades humanas). Todo ello con el objetivo de retomar una consciencia de especie y de solidaridad como fuente de bienestar. 
Explorando caminos hasta ahora vetados por los leviatanes autoritarios a los que invocara Hardin, y que, como analizara Ostrom, estarán más caracterizados por la relocalización y el cooperativismo a la hora de entendernos, de entrelazarnos y de hacer uso solidariamente de los recursos (¡bienes comunes!) de este planeta.

\section{Bibliografía básica sobre bienes comunes, democracia y movimientos sociales}

Aguilera Klink, F. y J. M. Naredo (2009): Economía, poder y megaproyectos, Teguise, Fundación César Manrique, Lanzarote.

Alonso, L. E. (2009): Prácticas económicas y economía de las prácticas. Crítica del postmodernismo liberal, La Catarata, Madrid.

Amaral Marques, P. (2011): La «Otra Economía» en movimiento: un estudio sociológico del movimiento social de la Economía Solidaria en Brasil, tesis Univ. Granada. Dep. de Sociología. Leída el 18 de nov. de 2011.

Arrighi, G.; Hopkins, T. K. y I. Wallerstein (1999): Movimientos antisistémicos, Tres Cantos, Madrid.

BARBER, B. (2004): Democracia fuerte, Almuzara, Madrid.

BECK, U. (2002): La sociedad del riesgo global, Siglo XXI de España, Madrid.

Boyle, J. (2003): El segundo movimiento de cercamiento y la construcción del dominio público. Disponible en <http: //www.elastico.net/copyfight/ upload/el_segundo_movimiento_de_cercamiento.pdf, consultado el 20 de abril de 2014>.

Calle Collado, A. (2007): «El estudio del impacto de los movimientos sociales. Una perspectiva global», Reis. Revista Española de Investigaciones Sociológicas, 120.

Calle Collado, A. (2009): «Democracia en movimiento», Relaciones Internacionales, 12, octubre. Disponible en $<$ www.relacionesinternacionales. info/revista/revista/N12/pdf/artcalle12.pdf $>$.

Calle Collado, A. (coord. 2011): Democracia radical. Entre vínculos y utopías, Catarata, Barcelona.

Calle Collado, A. (2013): La transición inaplazable. Los nuevos sujetos políticos para salir de la crisis, Icaria, Barcelona.

Candón Mena, J. (2013): Toma la calle, toma las redes: El movimiento 15M en Internet, Atrapasueños, Sevilla.

CARPINTERo, O. (2005): El metabolismo de la economía española: Recursos naturales y huella ecológica (1955-2000), Fundación César Manrique, Lanzarote. 
Carrasco, C.; C. Borderías y T. Torns (2011): El trabajo de cuidados. Historia, teoría y políticas, Catarata, Madrid.

Castillo, J. A. (2008): La soledad del trabajador globalizado, Catarata, Madrid.

Castillo, J. J.; R. Caravantes Vidriales; D. García Aristegui; C. González García y R. Lleó Fernández (2013): ¿Qué hacemos para que las diversas formas de trabajar sean coherentes con nuestras necesidades y no sea el mercado quien decide qué y cómo es el trabajo?, no 9 de la colección ¿Qué hacemos con...?, Akal, Madrid.

Coraggio, J. L.; A. Caillé; J-L. Laville y C. Ferraton (2009): ¿Qué es lo económico? Materiales para un debate necesario contra el fatalismo, ciccus, Buenos Aires.

Coraggio, J. L. (2011): Economía Social y Solidaria: El trabajo antes que el capital, Abya Yala/FLACso/Fundación Rosa Luxemburg, Quito.

Damasio, A. (2005): En busca de Spinoza. Neurobiología de la emoción y de los sentimientos. Crítica, Barcelona.

Della Porta, D. y T. Sidney (eds.) (2005): Transnational Protest and Global Activism, Rowman and Littlefield, New York.

Della Porta, D. (ed.) (2009): Democracy in Social Movements, Palgrave, London.

Escobar, A. (2000): «El lugar de la naturaleza y la naturaleza del lugar: ¿globalización o postdesarrollo?», en: La colonialidad del saber: eurocentrismo y ciencias sociales. Perspectivas latinoamericanas. Edgardo Lander (comp.), Clacso, Consejo Latinoamericano de Ciencias Sociales, Buenos Aires.

Ezquerra, S. (2013): «Economic Crisis and the New Enclosure of the Reproductive Commons in Spain», Monthly Review.

Federicci, S. (2010): Calibán y la bruja. Mujeres, cuerpo y acumulación primitiva, Traficantes de Sueños, Madrid.

Fernández Durán, R. (2011): La quiebra del capitalismo global: 2000-2030. Preparándonos para el comienzo del colapso de la civilización industrial, Virus/Ecologistas en Acción/Baladre, Barcelona.

Fuster Morell, M. (2011): «Participación en comunidades online y democracia radical», en CALLE, A. (coord., 2011).

Galcerán, M. (2011): «La dimensión democrática radical del feminismo», en Calle, A. (coord., 2011).

GallaR, D.(2013): «Economías campesinas como cultura a rescatar», Soberanía Alimentaria, $\mathrm{n}^{\mathrm{o}} 12$, pp. 18-22. 
GonzÁlez Reyes, L. (2013): «Sostenibilidad y bienes comunes», El Ecologista, $\mathrm{n}^{\mathrm{o}} 78$.

Graham, G. (2011): Una política poscapitalista, Siglo del hombre editores, Bogotá.

Guerra Palmero, M. J. (2004): «Ecofeminismos: la sostenibilidad de la vida humana como problema», en Riechmann (coord.): Ética ecológica. Propuestas para una reorientación, Norman Comunidad, Montevideo.

Harris, M. (1997): Nuestra especie, Alianza Editorial, Madrid.

Harvey, D. (2007): Espacios del capital. Hacia una geografía crítica, Akal, Madrid.

Heinberg, R. (2006): Se acabó la fiesta. Guerra y colapso económico en el umbral del fin de la era del petróleo, Barrabes, Huesca.

Herrero, Y.; F. Cembranos y M. Pascual (2011): Cambiar las gafas para mirar el mundo. Una nueva cultura de la sostenibilidad, Libros en Acción, Madrid.

IPPOLITA (2012): En el acuario de Facebook. El irresistible ascenso del anarco-capitalismo, Enclave, Madrid.

Marañón-Pimentel, B. (coord.) (2012), Solidaridad económica y potencialidades de transformación, ClACSO, Buenos Aires.

Mattei, U. (2013): Bienes Comunes. Un manifiesto, Trotta, Madrid.

Martínez, R. (2013): «La ilusión de los bienes comunes. Cierto, pero...» en el blog del autor, Ley Seca, <http://leyseca.net/la-ilusion-de-los-bienescomunes-cierto-pero/ consultado 16 de mayo 2013>.

Mellor, M. (2000): Feminismo y ecología, Siglo xxı, México.

Mies, M. y V. Shiva (1997): Ecofeminismo, Icaria, Barcelona.

Naredo, J. M. (1996): La economía en evolución. Historia y perspectivas de las categorías básicas del pensamiento económico, Siglo XXI, reed. actualizada, México-Madrid,

Núñez del Prado, J. (2009): Economías indígenas: estados del arte desde Bolivia y la economía política, CIDES-UMSA, Bolivia.

Orozco Pérez, A. (2006): Perspectivas feministas en torno a la economía: la crisis de los cuidados, Ed. Consejo Económico y Social, Madrid.

Orozco Pérez, A. (2010): «Insostenibilidad del sistema global de cuidados y alternativas feministas», en Mujeres, sexo, poder, economía y ciudadanía, Fórum de la Política Feminista, Madrid.

Pérez Vitoria, S. (2010): El retorno de los campesinos, Icaria, Barcelona. 
Petrella, R. (2009): «Los bienes comunes, patrimonio de la humanidad», Agenda Latinoamericana. Disponible en <http://www.servicioskoinonia. org/agenda/archivo/obra.php?ncodigo $=653>$ [consultado en febrero de 2014].

Plataforma Auditoría Ciudadana de la Deuda (coord. 2013): ¿Por qué no debemos pagar la deuda? Razones y Alternativas, Icaria, Barcelona.

Ploeg, J. D. VAn Der, (2011): Los nuevos campesinos, Icaria, Barcelona.

Porto Gonçalves, C. W. (2003): Geo-grafías: movimientos sociales, nuevas territorialidades y sustentabilidad, Siglo XxI, Buenos Aires.

Quiroga Díaz, N. (2009): «Economías feminista, social y solidaria. Respuestas heterodoxas a la crisis de reproducción en América Latina», Iconos: revista de Ciencias Sociales, FLACSO sede Ecuador, $\mathrm{n}^{\circ} 33$, Quito.

Razeto M. L. (1995): Los caminos de la economía de solidaridad, Funlam, Medellín.

Rendueles, C. (2013): Sociofobia, Capitán Swing, Madrid.

Ricoveri, G. (2012): Bens Comuns versus Mercadorias, Multifoco, Rio de Janeiro.

Riechmann, J. (2013): ¡Peligro! Hombres trabajando, Catarata, Madrid.

Sádaba, I.; M. Domínguez; J. Rowan; R. Martínez y Zemos98 (2013): La tragedia del copyright. Bien común, propiedad intelectual y crisis de la industria cultural, Virus, Barcelona.

SAssen, S. (2008): Una sociología de la globalización, Katz, Buenos Aires.

SENneTt, R. (2000): La corrosión del carácter. Las consecuencias personales del trabajo en el nuevo capitalismo, Anagrama, Barcelona.

SENNETt, R. (2013): Juntos. Rituales, placeres y políticas de cooperación, Anagrama, Barcelona.

Sevilla Guzmán, E. (2006): De la sociología rural a la agroecología, Icaria, Barcelona.

SiliPRANDi, E. (2009): «Um olhar ecofeminista sobre as lutas por sustentabilidade no mundo rural», en Petersen (Org.): Agricultura familiar camponesa na construçao do futuro, Revista Agriculturas, Rio de Janeiro.

Sousa SAntos, B. (2003): La caída del Angelus Novas. Ensayos para una teoría social y nueva práctica política, ILSA, Bogotá.

Sousa SANTos, B. (2011): Una epistemología del Sur. La reinvención del conocimiento y la emancipación social, CLACSO y Siglo XXI, México.

Subirats, J. (2012): Otra Sociedad. ¿Otra política? De «no nos representan» a la democracia de lo común, Icaria, Barcelona. 
SubiRaTs, J. (2013): «Bienes comunes y contemporaneidad. Releyendo a Polanyi», Ecología política, ${ }^{\circ} 45$.

SvamPa, M. (2011): «Extractivismo neodesarrollista y movimientos sociales. ¿Un giro ecoterritorial hacia nuevas alternativas?» en Más allá del Desarrollo, coord. por el Grupo Permanente de Trabajo sobre Alternativas al Desarrollo, Fundación Rosa Luxemburg.

Tanuro, D. (2011): El imposible capitalismo verde. Del vuelco climático capitalista a la alternativa socialista, Torrejón de Ardoz (Madrid), editado por Viento Sur y La Oveja Roja.

TAPIA, N. (2006): Agroecología y agricultura campesina sostenible en los Andes bolivianos: el caso del ayllu Majasaya-Mujlli, departamento de Cochabamba, Plural editores, La Paz.

TAPIA, L. (2009): «Lo político y lo democrático en los movimientos sociales»" en Tapia (coord.) Democracia y teoría política en movimiento, Muela del Diablo/CIMSA, La Paz.

Tapscott, D. y A. D. Williams (2007): Wikinomics: la nueva economía de las multitudes inteligentes, Ediciones Paidós Ibérica, Barcelona.

Toledo, V. M. y N. Barrera-Basols (2009): La memoria biocultural: la importancia ecológica de las sabidurías tradicionales, Icaria, Barcelona.

Torres, J. y L. Gálvez (2010): Desiguales: Mujeres y Hombres ante la crisis financiera, Icaria, Barcelona.

Ziвechi, R. (2011): Política y miseria, La Vaca y Málaga, Baladre-Zambra, Buenos Aires.

Zubero, I. (2013): De los «comunales» a los «commons»: la peripecia teórica de una práctica ancestral cargada de futuro, Documentación Social, $\mathrm{n}^{\circ} 165$.

\section{Anexo I}

TABLA 1. Algunas experiencias en las economías de los bienes comunes

\begin{tabular}{|c|c|c|c|c|c|}
\hline \multicolumn{2}{|r|}{ Actividad } & Trabajo & Democratización & Bienes ambientales & Bienes cooperativos \\
\hline \multicolumn{6}{|c|}{ Prosumidores } \\
\hline $\begin{array}{l}\text { La Tejedora, } \\
\text { CO }\end{array}$ & Mercado social & $\begin{array}{l}4 \text { empleos y } 2 \\
\text { voluntarios } \\
20 \text { personas en } \\
\text { comisiones } \\
\text { Red de productores y } \\
\text { artesanos }\end{array}$ & $\begin{array}{l}\text { Asamblea de } 150 \text { socios } \\
\text { Espacio de autogestión social } \\
\text { Regulación consensuada de precios }\end{array}$ & $\begin{array}{l}\text { Producción local, en su } \\
\text { mayor parte ecologica } \\
\text { Trabajo con } \\
\text { cooperativas afines }\end{array}$ & $\begin{array}{l}\text { Apertura del mercado en } \\
\text { el centro de la ciudad. } \\
\text { Salón para actividades } \\
\text { culturales y políticas }\end{array}$ \\
\hline $\begin{array}{l}\text { Red Producto- } \\
\text { res-Consumi- } \\
\text { dores, CO }\end{array}$ & $\begin{array}{l}\text { Comercia- } \\
\text { lización }\end{array}$ & $\begin{array}{l}\text { Voluntarios en } 6 \text { grupos, } \\
\text { que organizan a unas } \\
60 \text { personas y a } 20 \\
\text { productores }\end{array}$ & $\begin{array}{l}\text { Certificación social de la cadena de } \\
\text { comercialización según criterios de } \\
\text { proximidad y ambientales } \\
\text { Asamblea }\end{array}$ & $\begin{array}{l}\text { Prioridad al consumo } \\
\text { ecológico y local }\end{array}$ & $\begin{array}{l}\text { Disponibilidad de un } \\
\text { espacio de intercambio }\end{array}$ \\
\hline $\begin{array}{l}\text { La Acequia, } \\
\mathrm{CO}\end{array}$ & $\begin{array}{l}\text { Cooperativa } \\
\text { agroecológica }\end{array}$ & $\begin{array}{l}1 \text { empleo } \\
\text { Voluntariado en las } \\
\text { tareas y gestión de la } \\
\text { cooperativa }\end{array}$ & $\begin{array}{l}\text { Grupos que se organizan a través } \\
\text { de una asamblea de enlace }\end{array}$ & $\begin{array}{l}\text { Circuito de } \\
\text { autoconsumo, } \\
\text { producción ecológica, } \\
\text { recuperación de } \\
\text { semillas }\end{array}$ & $\begin{array}{l}\text { Disponibilidad de un } \\
\text { espacio de autogestión } \\
\text { para circuitos de } \\
\text { cortos de producción y } \\
\text { consumo }\end{array}$ \\
\hline
\end{tabular}




\begin{tabular}{|c|c|c|c|c|c|}
\hline & Actividad & Trabajo & Democratización & Bienes ambientales & Bienes cooperativos \\
\hline \multicolumn{6}{|c|}{ Biodiversidad y prod. sustentable } \\
\hline $\begin{array}{l}\text { Red de } \\
\text { Semillas, SE }\end{array}$ & $\begin{array}{l}\text { Semillas } \\
\text { locales }\end{array}$ & $\begin{array}{l}3 \text { personas más ligadas } \\
\text { proyectos }\end{array}$ & $\begin{array}{l}\text { Difusión, acceso y reproducción de } \\
\text { semillas locales } \\
\text { Creación de núcleos locales y } \\
\text { ferias de intercambio }\end{array}$ & $\begin{array}{l}\text { Bases para la } \\
\text { biodiversidad agrícola }\end{array}$ & \begin{tabular}{|l|} 
Bases para el libre \\
intercambio de material \\
genético \\
Incidencia política par \\
a la democratización de \\
este material \\
\end{tabular} \\
\hline La Verde, CA & $\begin{array}{l}\text { Producción } \\
\text { agro ecológica }\end{array}$ & $\begin{array}{l}\text { Cooperativismo } \\
\text { tradicional }\end{array}$ & $\begin{array}{l}\text { Biodiversidad cultivada accesible a } \\
\text { otros productores } \\
\text { Creación de canales de distribución } \\
\text { ecológica }\end{array}$ & $\begin{array}{l}\text { Biodiversidad } \\
\text { y producción } \\
\text { agroecológica }\end{array}$ & \begin{tabular}{|l|} 
Creación de \\
conocimiento para \\
la producción \\
agroecológica, banco de \\
semillas, etc.
\end{tabular} \\
\hline $\begin{array}{l}\text { La Chanca, } \\
\text { CA }\end{array}$ & $\begin{array}{l}\text { Pesca } \\
\text { Sustentable }\end{array}$ & $\begin{array}{l}\text { Cooperativismo } \\
\text { tradicional }\end{array}$ & & $\begin{array}{l}\text { Biodiversidad y } \\
\text { producción ecológica } \\
\text { pesquera }\end{array}$ & \begin{tabular}{|l|} 
Integrante grupos de \\
desarrollo de proyectos \\
de pesca sustentable
\end{tabular} \\
\hline $\begin{array}{l}\text { Som Energía, } \\
\text { grupos de } \\
\text { Andalucía }\end{array}$ & $\begin{array}{l}\text { Energía } \\
\text { renovables }\end{array}$ & Cooperativa de socios & $\begin{array}{l}\text { Asamblea general, comisiones de } \\
\text { trabajo y grupos locales de difusión }\end{array}$ & $\begin{array}{l}\text { Energía de fuentes } \\
\text { renovables }\end{array}$ & $\begin{array}{l}\text { Condiciones de } \\
\text { cooperación entre } \\
\text { productores y } \\
\text { consumidores para el } \\
\text { desarrollo de energías } \\
\text { limpias }\end{array}$ \\
\hline \multicolumn{6}{|c|}{ Conocimiento } \\
\hline $\begin{array}{l}\text { Wikanda, } \\
\text { Andalucía }\end{array}$ & $\begin{array}{l}\text { Divulgación } \\
\text { sobre el } \\
\text { territorio } \\
\text { andaluz } \\
\end{array}$ & $\begin{array}{l}\text { Núcleo dinamizador } \\
\text { Voluntariado } \\
\text { sosteniendo artículos }\end{array}$ & Acceso libre publicación & & Información \\
\hline Floqq & Educación P2P & Plataforma & $\begin{array}{l}\text { Contacto directo entre profesores y } \\
\text { estudiantes }\end{array}$ & $\begin{array}{l}\text { Utilización } \\
\text { herramientas on-line }\end{array}$ & $\begin{array}{l}\text { Colaboración en la } \\
\text { producción de cursos y } \\
\text { materiales } \\
\text { Acceso a educación }\end{array}$ \\
\hline \multicolumn{6}{|c|}{ Comunicación } \\
\hline $\begin{array}{l}\text { Guifi.net, nodo } \\
\text { SE }\end{array}$ & $\begin{array}{l}\text { Operador de } \\
\text { telecomu- } \\
\text { nicaciones }\end{array}$ & $\begin{array}{l}\text { Núcleo dinamizador, } \\
\text { existe Fundación }\end{array}$ & $\begin{array}{l}\text { "Es un proyecto colaborativo } \\
\text { organizado horizontalmente } \\
\text { que aglutina a personas } \\
\text { individuales, colectivos, empresas, } \\
\text { administraciones y universidades }\end{array}$ & & $\begin{array}{l}\text { red abierta para la } \\
\text { construcción enlaces } \\
\text { para internet } \\
\text { (Licencia Procomún de } \\
\text { Red Abierta Procomún } \\
\text { de la XOLN) } \\
\end{array}$ \\
\hline $\begin{array}{l}\text { Andalibre, } \\
\text { Andalucía }\end{array}$ & $\begin{array}{l}\text { Asociación de } \\
\text { Empresas de } \\
\text { Software Libre } \\
\text { de Andalucía }\end{array}$ & Empresas formales & $\begin{array}{l}\text { promocionar, organizar, coordinar, } \\
\text { apoyar y dirigir acciones de } \\
\text { divulgación del uso del Software } \\
\text { Libre y los Estándares Abiertos a } \\
\text { través de los diversos medios a los } \\
\text { que acceda }\end{array}$ & & $\begin{array}{l}\text { Acceso libre a tecnología } \\
\text { social } \\
\text { Incidencia política para } \\
\text { la democratización del } \\
\text { sector }\end{array}$ \\
\hline \multicolumn{6}{|l|}{ Culturales } \\
\hline $\begin{array}{l}\text { Asociación } \\
\text { Andaluza del } \\
\text { Circo }\end{array}$ & $\begin{array}{l}\text { Artes } \\
\text { Escénicas }\end{array}$ & Asamblea & Difusión de un patrimonio cultural & $\begin{array}{l}\text { Criterios ambientales } \\
\text { y de protección de } \\
\text { animales }\end{array}$ & \begin{tabular}{|l||} 
Espacio de acceso \\
libre dentro de las artes \\
escénicas
\end{tabular} \\
\hline \multicolumn{6}{|l|}{ Finanzas } \\
\hline $\begin{array}{l}\text { Coop57 } \\
\text { (Andalucía) }\end{array}$ & $\begin{array}{l}\text { Cooperativa de } \\
\text { préstamos }\end{array}$ & Núcleo dinamizador & $\begin{array}{l}\text { Asamblea socios colaboradores } \\
\text { Consejo, Comisión social y } \\
\text { comisión económica } \\
\text { Control social de préstamos }\end{array}$ & $\begin{array}{l}\text { Priorización } \\
\text { sostenibilidad }\end{array}$ & $\begin{array}{l}\text { Acceso a crédito para } \\
\text { iniciativas de escasa } \\
\text { aceptación por la banca } \\
\text { tradicional }\end{array}$ \\
\hline $\begin{array}{l}\text { Goteo.org } \\
\text { (Andalucía) }\end{array}$ & $\begin{array}{l}\text { Financiación, } \\
\text { crowdfunding }\end{array}$ & Núcleo dinamizador & $\begin{array}{l}\text { Participación directa en el apoyo } \\
\text { a proyectos que se ofertan vía } \\
\text { internet }\end{array}$ & & $\begin{array}{l}\text { Acceso a crédito directo } \\
\text { a través de proyectos que } \\
\text { se exponen en internet }\end{array}$ \\
\hline Jara (Aljarafe) & Moneda social & Núcleo dinamizador & $\begin{array}{l}\text { Asamblea de dinamización } \\
\text { Control social de la moneda }\end{array}$ & $\begin{array}{l}\text { Energía, vivienda, } \\
\text { textil, alimentación } \\
\text { (producción y } \\
\text { reciclaje) } \\
\text { Autogestión de la } \\
\text { salud, educación }\end{array}$ & $\begin{array}{l}\text { Mercado basado en } \\
\text { trueques e intercambios }\end{array}$ \\
\hline \multicolumn{6}{|c|}{ Centros sociales } \\
\hline $\begin{array}{l}\text { La Casa Azul, } \\
\mathrm{CO}\end{array}$ & $\begin{array}{l}\text { Espacio social } \\
\text { autogestionado }\end{array}$ & $\begin{array}{l}4 \text { empleos (informales) } \\
\text { Red de productores } \\
\text { y artesanos que } \\
\text { comercializan en sus } \\
\text { Tianguis } \\
\text { Servicios (textil, } \\
\text { masajes) }\end{array}$ & Asamblea de socios, 20 personas & $\begin{array}{l}\text { Promoción mercados } \\
\text { ecológicos } \\
\text { Consumo de productos } \\
\text { ecológicos }\end{array}$ & $\begin{array}{l}\text { Acceso de iniciativas } \\
\text { políticas, culturales y } \\
\text { productivas a un espacio } \\
\text { en el centro de la ciudad } \\
\text { de Córdoba }\end{array}$ \\
\hline \multicolumn{6}{|c|}{ Bancos Tiempo } \\
\hline $\begin{array}{l}\text { Redes de } \\
\text { trueque de } \\
\text { Córdoba }\end{array}$ & $\begin{array}{l}\text { Consumo } \\
\text { colaborativo } \\
\text { (trueque) }\end{array}$ & $\begin{array}{l}\text { Voluntariado } \\
\text { dinamizador asociado a } \\
\text { tejido social de la ciudad }\end{array}$ & Mercado abierto & Reciclaje de bienes & $\begin{array}{l}\text { Intercambios sin } \\
\text { monedas }\end{array}$ \\
\hline \multicolumn{6}{|c|}{ Necesidades materiales } \\
\hline $\begin{array}{l}\text { Habitares, } \\
\text { Andalucía }\end{array}$ & $\begin{array}{l}\text { Arquitectura y } \\
\text { Vivienda }\end{array}$ & Voluntariado & $\begin{array}{l}\text { Asamblea de técnicos y técnicas } \\
\text { Acompañamiento de iniciativas }\end{array}$ & $\begin{array}{l}\text { Visión de } \\
\text { sostenibilidad } \\
\text { ambiental en materiales } \\
\text { y energía }\end{array}$ & $\begin{array}{l}\text { Promoción del } \\
\text { cooperativismo en } \\
\text { vivienda }\end{array}$ \\
\hline $\begin{array}{l}\text { La Vuelta al } \\
\text { mundo, } \mathrm{CO}\end{array}$ & $\begin{array}{l}\text { Servicios } \\
\text { transporte en } \\
\text { bicicleta }\end{array}$ & 3 empleos & Cooperativa de socios & $\begin{array}{l}\text { Envíos y promoción de } \\
\text { la sostenibilidad }\end{array}$ & $\begin{array}{l}\text { Información y difusión } \\
\text { de alternativas de } \\
\text { transporte }\end{array}$ \\
\hline
\end{tabular}

